\title{
Evaluation of C-Reactive Protein and Associated Factors Among Patients Suffering from Rheumatoid Arthritis at Tikur Anbessa Specialized Hospital, Addis Ababa, Ethiopia
}

\author{
Gashaw Dessie (iD) \\ Yewondwossen Tadesse ${ }^{2}$ \\ Birhanu Demelash ${ }^{2}$ \\ Solomon Genet ${ }^{3}$ \\ Tabarak Malik (iD) \\ Tadesse Asmamaw Dejenie (D) \\ 'Department of Biochemistry, School of \\ Medicine, College of Medicine and Health \\ Sciences, University of Gondar, Gondar, \\ Ethiopia; ${ }^{2}$ Department of Internal \\ Medicine, School of Medicine, Addis \\ Ababa University, Addis Ababa, Ethiopia; \\ ${ }^{3}$ Department of Biochemistry, School of \\ Medicine, College of Health Sciences, \\ Addis Ababa University, Addis Ababa, \\ Ethiopia
}

Background: Rheumatoid arthritis (RA) is a chronic autoimmune inflammatory disorder, which is associated with increased pro-inflammatory mediators to induce an elevation in acute-phase response, migration of immune cells and swelling of synovial joints. Evaluation of the level of C-reactive protein and associated risk factors in RA patients was the main aim of this study. Identifying the association between disease activity of RA (hsCRP) and sociodemographic characteristics was another aim of the study.

Methods: Institution-based cross-sectional study was conducted at the Rheumatology Clinic of Tikur Anbessa Specialized Hospital. In this study, the level of hsCRP was measured in both case and control groups. Simple descriptive statistics, multivariate analysis, independent sample $t$-test were utilized for statistical analysis. The strength of association between different risk factors and hsCRP was measured using odds ratio and $95 \%$ confidence interval. P-value $<0.05$ was considered as statistically significant.

Result: The result of this study showed that the hsCRP level was significantly higher among RA patients as compared to the control groups $(\mathrm{P}$-value $=0.004)$. There was an association between smoking and high disease activity status $(A O R=20.03, p=0.40)$. Low economic status had a statistically significant association with high hsCRP level (AOR $=12.79$, $\mathrm{p}=0.00$ ). In this study, $42 \mathrm{RA}$ patients had $>3 \mathrm{mg} / \mathrm{l}$ hsCRP level with different occupational exposures. On the other hand, $31 \mathrm{RA}$ patients had $<3 \mathrm{mg} / 1 \mathrm{hsCRP}$ level among different exposures. Although there was no statistically significant association, the association between associated risk factors (oil consumption, physical exercise, educational status) and disease activity was computed in this study.

Conclusion: The inflammatory marker, hsCRP was significantly higher among patients as compared to controls. The higher hsCRP showed a high grade of systemic inflammation in RA patients. C-reactive protein was elevated in rheumatoid factor positive patients and patients with high BMI value. Additionally, the result of our study showed that different socio-economic factors had an association with disease activity of RA.

Keywords: rheumatoid arthritis, disease activity, C-reactive protein

\section{Introduction}

Rheumatoid arthritis (RA) is a chronic autoimmune inflammatory disorder, which is associated with increased pro-inflammatory mediators to induce an elevation in acute-phase response, migration of immune cells, and swelling of synovial joints. ${ }^{1}$ Thus, chronic inflammation in synovial joint leads to systemic complication and
Department of Biochemistry, School of Medicine, College of Medicine and Health Sciences, University of Gondar, Gondar, Ethiopia

Tel +25I $975 I 52796$

Email dessiegashaw@yahoo.com 
destruction of joints. ${ }^{2}$ The disease activity score in RA patients can be measured using both $\mathrm{C}$-reactive protein (CRP) and erythrocyte sedimentation rate (ESR). ${ }^{3}$ The binding of CRP to Fc portion of immunoglobulin activates the synthesis of pro-inflammatory cytokines, which contribute to the pathogenesis of chronic inflammation. ${ }^{2}$ The disease activity score (DAS) has been associated with multi-biochemical marker, including CRP level. ${ }^{4}$ Disease activity score-28 (DAS-28) utilizes both CRP and ESR to measure disease activity in RA patients. DAS-28 CRP is mostly applied as compared to DAS-28 ESR due to its decreased confounding effect. ${ }^{5}$

The risk of RA is mostly associated with low socioeconomic level of patients, including low educational status. ${ }^{6}$ The study conducted in China showed that disease activity in RA patients had a significant association with educational levels. ${ }^{7}$ The risk of RA elevated in patients with low-income status. ${ }^{8}$ On the other hand, smoking habits and sex (females) are some of the exposure risk factors for the pathogenesis of RA. ${ }^{9}$ Expression of pro-inflammatory cytokines may be elevated in an individual with smoking habit, which account for the pathogenesis of RA. ${ }^{10}$ The association of disease activity, treatment efficacy, and antibodies with smoking is not clearly defined in different types of studies. ${ }^{11}$ However, researchers showed that RA patients with smoking habit developed a high disease activity, fatigue, and pain as compared to the non-smoker one. ${ }^{12}$ On the other hand, diets may elevate the risk of RA by mediating systemic inflammation. ${ }^{13}$ The risk of the disease is elevated in patients who consumed diets with high amount of trans and saturated fatty acids. ${ }^{14}$ Thus, the risk of RA becomes elevated by 2.29 in patients with high solid oil consumption. $^{15}$ In contrast to this, the burden of RA diminished in consumption of diets with high content of omega-3 fatty acids, including Olive oil and fish oil. ${ }^{16}$ Additionally, the risk of RA is expected to be elevated in the farming area with pesticides. ${ }^{17}$ The occupational exposures to pesticides, mineral oils, and silica are some of the risk factors for the pathogenesis of RA. ${ }^{18}$ On the other hand, the risk of RA increased among alcoholic drinkers with citrullinated protein antigen (ACPA) positive patients. ${ }^{19}$ A number of studies describe physical activity as a factor to decrease the level of hsCRP in arthritis patients. ${ }^{20}$ Occupational exposure, low economic status and level of education are some of socio-economic factors, which are associated with risk of RA. $^{21}$ Although the inflammatory marker in RA patient has been assessed earlier, there is no adequate comprehensive study done in Ethiopia regarding disease activity and its association with socio-demographic factors. Therefore, evaluation of disease activity using biochemical marker (hsCRP) and associated factors was the aim of this study. The study also analyzed the association between socio-demographic factors with disease activity status of RA patients.

\section{Materials and Methods Objective of Study}

Evaluation of the level of C-reactive protein and associated risk factors in RA patients was the main aim of this study. Identifying the association between disease activity of RA (hsCRP) and socio-demographic characteristics was another aim of the study.

\section{Study Design}

The institutional-based comparative cross-sectional study design was utilized during the study period. The study was taken place at Tikur Anbessa Specialized Hospital, which is the largest referral hospital in Ethiopia. The study was conducted from June up to November 2018.

\section{Study Population}

All RA patients with early and active stages of the disease were selected as the study population. Patients having the inclusion parameters of American College of Radiology and European League Against Rheumatism (ACR/ EULAR) were included in this study. Patients were diagnosed by senior physicians using clinical and biochemical identification parameters.

\section{Patients' Inclusion and Exclusion Parameters}

In this study, RA patients with different disease activity status were included. Patients who did not provide the complete information or data were excluded. In this regard, patients with less than 18 years old and with other psychological disorders were also excluded from this study. On the other hand, patients who had chronic diseases including diabetes and cancer were excluded.

\section{Control Group Inclusion and Exclusion Parameters}

The apparently healthy individuals who had no chronic diseases, including hypertension, tuberculosis, RA, and 
diabetes mellitus, were included as control groups during this investigation. Study participants were selected from the hospital staff and other healthy individuals who took care of patients in the hospital. Similar to case groups, study subjects who provided inadequate information were excluded.

\section{Blood Sample Collection Process and Data Collection Procedure}

Measurement of C-reactive protein was conducted after the overnight fasting condition to avoid misinterpretation of laboratory investigation. The procedure of laboratory investigation includes the collection of an appropriate level of blood, centrifugation at 3500 revolutions per minute (rpm) and finally preservation of sample until biochemical parameter analysis was done. On the other hand, well-structured open-ended questionnaire was utilized to assess the associated risk factors in RA patients. Data were collected by using data collectors with one supervisor. One-day training was provided for data collectors and supervisor on research methodology, data collection technique, ethical issues. The questionnaire was checked for completeness, and the overall data collection processes were monitored by the principal investigator.

\section{Data Analysis Procedure}

Data was transcribed into computer information from the completed questionnaire, and then data coded, edited, cleaned and analyzed using SPSS version 20 software for analysis. Descriptive analysis was performed, and the results presented in the form of tables and figures, multi variable linguistic regression. The socio-demographic characteristics of study participants (occupation, education, income, smoking, alcohol drinking, physical activity and others) were analyzed using simple descriptive statistics. The socio-demographic and clinical characteristics were compared among case and control groups using independent sample $t$-test. It was performed using step-wise methods to identify factors independently associated with the dependent variable. The strength of association was measured using odds ratio and $95 \%$ confidence interval. P-value $<0.05$ was considered as statistically significant.

\section{Result}

\section{Socio-Demographic Characteristics}

In this study, 73 RA patients and 40 apparently healthy study subjects were involved. Of the total patients, 9
$(12.4 \%)$ and $64(87.6 \%)$ were male and females, respectively. Thirty-eight (52\%) patients failed under the age category of 40-59 years old. Regarding the occupational exposure, 34 (46.5\%), 08 (10.9\%), 11 (16.3\%) patients had housewife, farmer and private occupation, respectively. Additionally, 17 (23.5\%), 23 (31.5\%) and 33 (45\%) patients were categorized as high-, middle- and lowincome status, respectively. Concerning the assessment of educational level, 19 (26\%), 22 (30\%), 20 (27\%), 12 $(17 \%)$ patients were illiterate, completed primary and school, college, respectively. The majority of patients were urban residents (89\%) (as shown in Table 1).

\section{Evaluation of hsCRP and Demographic Characteristics Among Case and Control Groups}

In this study, the Mean \pm SD of hsCRP level among cases and control groups were $10.54 \pm 17.26$ and $3.54 \pm 7.60$, respectively. Additionally, the Mean \pm SD of body mass index of RA patients and apparently healthy control groups were $23.25 \pm 3.67$ and $23.87 \pm 3.77$, respectively. On the other hand, there was a statistically significant demographic difference between patients and controls regarding occupation and monthly income. The level of high sensitivity C-reactive protein showed a statistically significant elevation among cases as compared to the control one Table 2 .

\section{Evaluation of Associated Risk Factors and Disease Activity in RA Patients}

Multivariate analysis was done on demographic associated risk factors to assess their association with disease activity of RA. The analysis of risk of RA patients was depended on the measurement of disease activity status. In this regard, patients with $<3 \mathrm{mg} / \mathrm{l} \mathrm{hsCRP}$ and $>3 \mathrm{mg} / \mathrm{l}$ hsCRP were categorized as low and high disease activity status, respectively. Low-income patients had a statistically significant association with high disease activity $(\mathrm{AOR}=12.79)$ as compared to high-income status patients. Additionally, patients with smoking habit, females, illiterate and occupational exposures are some of the associated risk factors with high disease activity (hsCRP $>3 \mathrm{mg} / \mathrm{dl}$ ) (as shown in Table 3).

\section{Comparison of Disease Activity Status of} RA Patients with Occupational Exposure

From the total enrolled RA patients, 3, 16, 6, 9 and 8 of them were industrial workers, housewives, farmers, government civil servants and private workers with high 
Table I Socio-Demographic Characteristics of RA Patients and Control Groups

\begin{tabular}{|c|c|c|c|}
\hline Characteristics & Category & Cases $(n=73)$ & Control $(n=40)$ \\
\hline \multirow[t]{3}{*}{ Age } & $20-39$ & $25(34.4 \%)$ & $15(37.5 \%)$ \\
\hline & $40-59$ & $38(52 \%)$ & $20(50 \%)$ \\
\hline & $60-79$ & $10(13.6 \%)$ & 5 (I2.5\%) \\
\hline \multirow[t]{2}{*}{ Sex } & Male & 9 (12.4\%) & $13(32.5 \%)$ \\
\hline & Female & $64(87.6 \%)$ & $27(67.5 \%)$ \\
\hline \multirow[t]{2}{*}{ Residence area } & Urban & $65(89 \%)$ & $26(65 \%)$ \\
\hline & Rural & $8(11 \%)$ & $14(35 \%)$ \\
\hline \multirow[t]{4}{*}{ Marital status } & Single & $18(24.6 \%)$ & 07 (I7.5\%) \\
\hline & Married & $40(54.7 \%)$ & $32(80 \%)$ \\
\hline & Divorced & 07 (9.5\%) & $0 \mathrm{I}(2.5 \%)$ \\
\hline & Death & $03(4.2 \%)$ & - \\
\hline \multirow[t]{4}{*}{ Educational status } & Illiterate & $19(26 \%)$ & $16(40 \%)$ \\
\hline & Complete primary school & $22(30 \%)$ & 05 (I2.5\%) \\
\hline & Complete secondary school & $20(27 \%)$ & $12(30 \%)$ \\
\hline & Complete college or university & $12(17 \%)$ & $17(42.5 \%)$ \\
\hline \multirow[t]{3}{*}{ Monthly income (ETB) } & Low $(<500)$ & $33(45 \%)$ & $9(12 \%)$ \\
\hline & Middle (500-1000) & $23(31.5 \%)$ & $12(16 \%)$ \\
\hline & High (> 1000) & $17(23.5 \%)$ & 19 (72\%) \\
\hline \multirow[t]{2}{*}{ Smoking } & Yes & 04 & 0 \\
\hline & No & 69 & 40 \\
\hline \multirow[t]{2}{*}{ Type of oil } & Solid oil & $29(39.7 \%)$ & 18 (45\%) \\
\hline & Liquid oil & $44(60.3)$ & $22(55 \%)$ \\
\hline \multirow[t]{3}{*}{ Alcohol } & No & $65(89 \%)$ & $35(87.5 \%)$ \\
\hline & Occasional & $08(11 \%)$ & 05 (I2.5\%) \\
\hline & Regular & 0 & 0 \\
\hline \multirow[t]{2}{*}{ Physical exercise } & Yes & 08 (10.9\%) & $02(5 \%)$ \\
\hline & No & $65(89.1 \%)$ & 38 (95\%) \\
\hline \multirow[t]{4}{*}{ Occupation } & Housewife & $34(46.5 \%)$ & $04(10 \%)$ \\
\hline & Farmer & 08 (10.9\%) & 07 (I7.5\%) \\
\hline & Government civil servant & $09(12.3 \%)$ & 18 (45\%) \\
\hline & Private worker & II (I6.3\%) & $12(30 \%)$ \\
\hline
\end{tabular}

Note: Descriptive analysis was utilized to compare socio-demographic factors among groups.

Abbreviation: ETB, Ethiopian birr.

disease activity status (42 RA patients with $>3 \mathrm{mg} / \mathrm{l}$ hsCRP level), respectively. On the other hand, 1, 19, 2, 5 and 4 patients had industry workers, housewives, farmers, government civil servants, and private worker occupation, respectively. They had lower disease activity status (31 RA patients with $<3 \mathrm{mg} / \mathrm{L}$ hsCRP) (as shown in Figure 1).

\section{Comparison of Disease Activity with Income of Study Participants}

Out of the total study participants, 26, 12 and 4 patients had high disease activity (42 patients with $>3 \mathrm{mg} / \mathrm{l}$ hsCRP) with their respective low-, medium- and high-income status. In contrast, 7, 11 and 13 patients had low disease activity ( 31 patients with $<3 \mathrm{mg} / \mathrm{l}$ hsCRP) with their respective low-, medium- and high-income status (as shown in Figure 2).

\section{Discussion}

Rheumatoid arthritis (RA) is a chronic autoimmune inflammatory disorder, which leads to the damage to joints with psychological, metabolic, and bone impact. ${ }^{22}$ Unless it is treated early, it induces the deformity of joints and 
Table 2 Comparison of hsCRP and Associated Factors Among Case and Control Group

\begin{tabular}{|l|l|l|l|l|}
\hline Characteristics & Case $(\mathbf{n}=\mathbf{7 3})$ & Controls $(\mathbf{n}=\mathbf{4 0})$ & $\mathbf{9 5 \%} \mathbf{C l}$ of the Difference & P-value \\
\hline BMI & $23.25 \pm 3.67$ & $23.87 \pm 3.77$ & $-2.07-0.85$ & 0.46 \\
hsCRP & $10.54 \pm 17.26$ & $3.54 \pm 7.60$ & $2.33-11.65$ & $0.004^{*}$ \\
RF & $4.24 \pm 0.43$ & $0 / 0$ & - & - \\
Physical exercise & $0.89 \pm 0.31$ & $0.95 \pm 0.22$ & $-0.16-0.41$ & 0.243 \\
Smoking habit & $1.94 \pm 0.22$ & $2.00 \pm 0.00$ & $-0.10-0.001$ & 0.45 \\
Oil consumption & $1.39 \pm 0.49$ & $1.57 \pm 0.50$ & $-0.37-0.17$ & 0.073 \\
Occupation & $2.93 \pm 1.25$ & $3.85 \pm 1.05$ & $-1.35-0.47$ & $0.00^{*}$ \\
Monthly income & $1.78 \pm 0.80$ & $2.25 \pm 0.80$ & $-0.78-0.15$ & $0.004^{*}$ \\
\hline
\end{tabular}

Notes: The Mean \pm SD values are estimated using independent $t$-test analysis. *Indicates the significant association as $P$-value $<0.05$.

Abbreviations: BMI, body mass index; hsCRP, high sensitivity C-reactive protein; RF, rheumatoid factor.

Table 3 Multivariable Logistic Regression of Associated Demographic Factors with High Disease Activity

\begin{tabular}{|c|c|c|c|}
\hline \multirow[t]{2}{*}{ Variables } & \multirow[t]{2}{*}{ Category } & \multicolumn{2}{|c|}{ High Disease Activity ( $>3 \mathrm{mg} / \mathrm{l}$ hsCRP) } \\
\hline & & AOR & P-value \\
\hline Sex & $\begin{array}{l}\text { Male } \\
\text { Female }\end{array}$ & $\begin{array}{l}\text { I } \\
0.64(0.14-2.79)\end{array}$ & 0.55 \\
\hline BMI & $\begin{array}{l}<25 \\
25.9-29.9 \\
>29.9\end{array}$ & $\begin{array}{l}\text { I } \\
\text { I. } 19(0.39-3.57) \\
0.75(0.99-5.81)\end{array}$ & $\begin{array}{l}0.75 \\
0.79\end{array}$ \\
\hline RF & $\begin{array}{l}\text { Non-reactive } \\
\text { Reactive }\end{array}$ & $\begin{array}{l}\text { I } \\
0.6(0.19-1.82)\end{array}$ & 0.36 \\
\hline Residence & $\begin{array}{l}\text { Rural } \\
\text { Urban }\end{array}$ & $\begin{array}{l}\text { I } \\
0.4 \text { I }(0.78-2.20)\end{array}$ & 0.30 \\
\hline Education & $\begin{array}{l}\text { Higher education } \\
\text { Illiterate } \\
\text { Primary school } \\
\text { Secondary School }\end{array}$ & $\begin{array}{l}\text { I } \\
\text { I.22 }(0.27-5.37) \\
\text { I.03 }(0.24-4.30) \\
0.71(0.16-3.02)\end{array}$ & $\begin{array}{l}0.78 \\
0.19 \\
0.64\end{array}$ \\
\hline Exercise & $\begin{array}{l}\text { No } \\
\text { Yes }\end{array}$ & I $0.71(0.16-3.09)$ & 0.64 \\
\hline Alcohol & $\begin{array}{l}\text { Never drinks } \\
\text { Some times }\end{array}$ & $6.00(0.69-51.57)$ & 0.10 \\
\hline Smoking & $\begin{array}{l}\text { No } \\
\text { Yes }\end{array}$ & $\begin{array}{l}1 \\
20.03\end{array}$ & 0.40 \\
\hline Oil type & $\begin{array}{l}\text { Liquid oil } \\
\text { Solid oil }\end{array}$ & I. $.48(0.57-3.82)$ & 0.41 \\
\hline Occupation & $\begin{array}{l}\text { Private worker } \\
\text { Industry worker } \\
\text { Housewife } \\
\text { Farmer } \\
\text { Government civil servant }\end{array}$ & $\begin{array}{l}\text { I } \\
1.50(0.11-19.43) \\
0.42(0.10-1.66) \\
1.50(0.20-11.08) \\
0.90(0.17-4.56)\end{array}$ & $\begin{array}{l}0.75 \\
0.21 \\
0.69 \\
0.89\end{array}$ \\
\hline Monthly income & $\begin{array}{l}\text { High income } \\
\text { Low } \\
\text { Middle }\end{array}$ & $\begin{array}{l}\text { I } \\
\text { I } 2.79(2.98-48.8 \mid) \\
3.54(0.88-\mid 4.19)\end{array}$ & $\begin{array}{l}0.00 * \\
0.07\end{array}$ \\
\hline
\end{tabular}

Note: *Indicates the significant association as P-value $<0.05$.

Abbreviations: BMl, body mass index; hsCRP, high sensitivity C-reactive protein; RF, rheumatoid factor). 


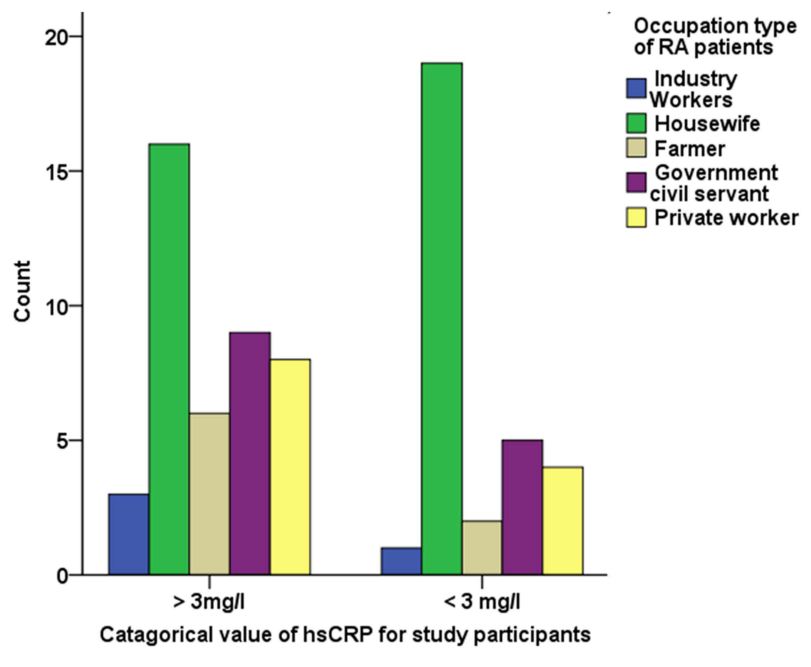

Figure I Comparison of disease activity status among occupational types.

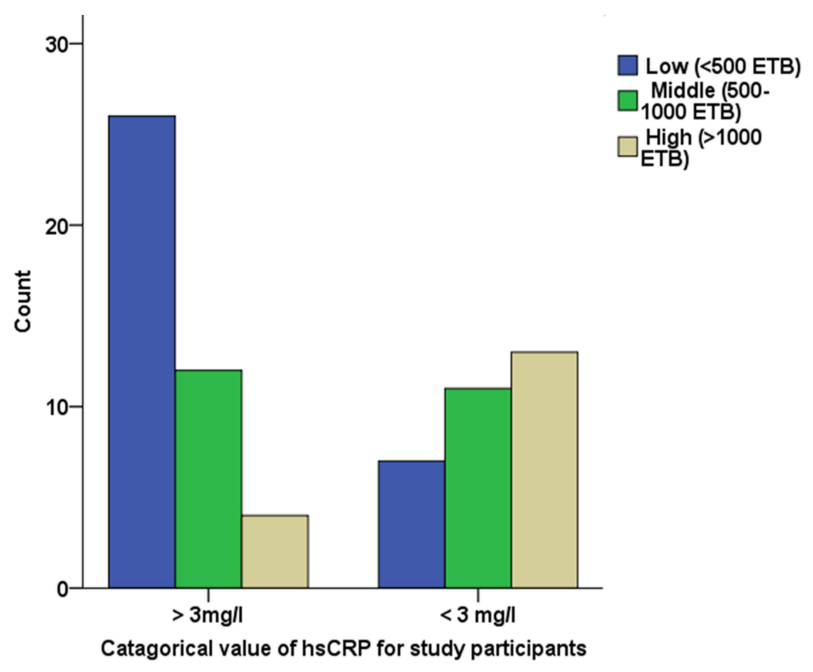

Figure 2 Comparison of disease activity of study participants with income status.

bones. $^{23,24}$ In this study, 73 RA patients and 40 age-sex matched apparently healthy study subjects were involved. Of the total RA patients, $9(12.4 \%)$ and 64 (87.6\%) were males and females, respectively (Table 1). The assessment of this study showed that females are more likely affected by RA. Hormonal and genetic factors may contribute to sexual variation in the prevalence of RA. ${ }^{25}$ Although there was no statistically significant variation, RA patients had a higher BMI index as compared to control groups. On the other hand, there was a statistically significant elevation of hsCRP among RA patients as compared to controls (Table 2). The result of this study is consistent with the previous investigation. ${ }^{26}$
In this study, the level of hsCRP was measured and utilized to measure disease activity status in RA patients. Patients with $<3 \mathrm{mg} / 1$ hsCRP level were regarded as low disease activity, whereas patients with $>3 \mathrm{mg} / \mathrm{l}$ hsCRP were categorized as high disease activity status. Disease activity evaluation using $\mathrm{C}$-reactive protein was supported by previous data. ${ }^{4}$ Although measurement of C-reactive protein is non-specific, it is utilized to evaluate disease activity status in RA patients. ${ }^{27}$ From the total RF reactive patients, 30 and 25 of them had high and lower disease activity status, respectively. Although there was no statistically significant association, the majority of RF reactive patients had high disease activity. The association between RF and disease activity has not well defined; however, researchers correlate its effect with the destruction of joint and cardiovascular disease. ${ }^{28,29}$ Additionally, there was a statistically significant variation regarding occupational exposure among RA patients as compared to apparently healthy individuals $(\mathrm{P}<0.00)$. The assessment of our study was similar to the original research done in Sweden. ${ }^{30}$ Similarly, a recent meta-analysis and systematic review revealed that occupational exposure contributes to the risk of RA. ${ }^{31}$ On the other hand, the monthly income of patients was assessed to evaluate its role in the risk of RA patients. There was a statistically significant variation regarding low economic status between case and control groups $(\mathrm{P}=0.00)$. Thus, it was in line with previous finding. ${ }^{32}$

In this study, industry workers, housewives, farmers, government civil servants, and private workers were involved to assess their disease activity status (Figure 1). The result of our study agreed with previous data. $^{33}$ On the other hand, the association between hsCRP with clinical and socio-demographic data has been analyzed. In this regard, RA patients with BMI value (25.9-29.9) were 1.19 times more likely to had high disease activity as compare to $<25$ BMI value. Thus, it was agreed with the earlier scientific data conducted in 2018. ${ }^{11}$ The research article done in Sweden confirmed that patients with high BMI value had high disease activity scores. ${ }^{11}$ On the other hand, 26, 12, and 4 of study participants had high disease activity with their respective low-, medium-, and high-income status (Figure 2). Patients with low economic status $(<500$ ETB) were 12.79 times more likely to have high disease activity as compared to high economic status individual $(>1000 \mathrm{ETB})$. There was a high statistical significant 
association between low-income status with high disease activity $(\mathrm{p}<0.00)$ (Table 3$)$. In line with our results, a case-control study conducted in Sweden confirmed that low socio-economic status and smoking contribute to the risk of $\mathrm{RA}^{21}$ The previous investigation from some developed countries showed that the pathogenesis of RA is affected through low socio-economic level. ${ }^{34}$ Additionally, smoker patients were 20.03 times more risky to have high disease activity as compared to the non-smoker one (Table 3). The association between smoking and disease activity may be due to its radiographic progression and generation of free radicals in tobacco. ${ }^{10,11}$ Regarding occupational exposure, farmers and industry workers were 1.50 times more likely to develop high disease activity as compared to private worker. The possible reason for their high disease activity status may be associated with their exposure to pesticides (farmer) and silica (industry worker). ${ }^{18}$ On the other hand, RA patients with solid oil consumption were 1.48 times more likely to have high disease activity score. However, there was no statistically significant association between consumption of solid oil with high disease activity. In line with our study, a case-control study done in Iran revealed that the risk of RA elevated by 2.29 due to consumption of solid oil. ${ }^{15}$ It may be due to the high proportion of saturated fatty acids within solid oil. ${ }^{15}$ Patients with occasional alcohol drinking habit $(\mathrm{AOR}=6.00)$ had more risk of RA as compared to non-drinker one. In contrast to our result, the recent systematic review and meta-analysis published in Scientific reports revealed that disease activity decreased in RA patients with alcohol consumption. ${ }^{19}$

\section{Conclusion}

The inflammatory marker, hsCRP, was significantly higher among patients as compared to controls. The higher hsCRP showed high grade of systemic inflammation in RA patients. The level of hsCRP was elevated in patients with rheumatoid factor seropositive and with high BMI value. Generally, the result of our study showed that different socio-economic factors had an association with the disease activity of RA. In this study, patients with lower income status had a statistically significant association with a high risk of RA. The low economic status may be associated with accessibility of good health facility and living standard. Therefore, avoiding poverty may decrease the risk of RA. Environmental risk factors (smoking, occupational exposure and habit of solid oil consumption) had an association with increased risk (high disease activity) of RA patients. Exposure to hazardous chemicals and saturated fatty acids may account for the pathogenesis of RA. Therefore, management of socio-economic factors may protect against severe disease activity and complication of RA.

\section{Abbreviations}

BMI, Body mass index; DAS, Disease activity score; hsCRP, High sensitivity C-reactive proteins; RA, Rheumatoid arthritis.

\section{Data Sharing Statement}

Data are available from the corresponding author on a reasonable request.

\section{Ethics Approval and Informed Consent}

Ethical approval was obtained by the research and ethics committee of the department of Biochemistry, School of Medicine, Addis Ababa University, Ethiopia. The Ethics and Research Committee reviewed and approved the protocol. This study was conducted in accordance with the Declaration of Helsinki. An example consent form is available from the corresponding author on a reasonable request. All participants provided informed consent.

\section{Acknowledgments}

We sincerely acknowledge the University of Gondar, Addis Ababa University, Tikur Anbessa Specialized Hospital for funding and support during the research work. We thank all the participants who were enrolled in this study.

\section{Author Contributions}

All authors made a significant contribution to the work reported, whether that is in the conception, study design, execution, acquisition of data, analysis and interpretation, or in all these areas; took part in drafting, revising or critically reviewing the article; gave final approval of the version to be published; have agreed on the journal to which the article has been submitted; and agree to be accountable for all aspects of the work.

\section{Funding}

Addis Ababa University funded this project to support graduate students. 


\section{Disclosure}

The authors declare that they have no conflicts of interest for this work.

\section{References}

1. Shafran IH, Alasti F, Smolen JS, Aletaha D. Implication of baseline levels and early changes of $\mathrm{C}$-reactive protein for subsequent clinical outcomes of patients with rheumatoid arthritis treated with tocilizumab. Ann Rheum Dis. 2020;79(7):874-882. doi:10.1136/ annrheumdis-2019-215987

2. Pope JE, Choy EH C-reactive protein and implications in rheumatoid arthritis and associated comorbidities. Paper presented at: Seminars in Arthritis and Rheumatism. 2020.

3. D'Cruz LG, McEleney KG, Cochrane C, et al. Assessment of a dried blood spot C-reactive protein method to identify disease flares in rheumatoid arthritis patients. Sci Rep. 2020;10(1):1-10. doi:10.1038/s41598-020-77826-0

4. Roodenrijs NM, de Hair MJ, Wheater G, et al. The multi-biomarker disease activity score tracks response to rituximab treatment in rheumatoid arthritis patients: a post hoc analysis of three cohort studies. Arthritis Res Ther. 2018;20(1):1-9. doi:10.1186/s13075-018-1750-5

5. Dhaon P, Das SK, Srivastava R, Dhakad U. Performances of Clinical Disease Activity Index (CDAI) and Simplified Disease Activity Index (SDAI) appear to be better than the gold standard Disease Assessment Score (DAS-28-CRP) to assess rheumatoid arthritis patients. Int $J$ Rheum Dis. 2018;21(11):1933-1939. doi:10.1111/ 1756-185X.13110

6. Gamal SM, Eleishi HH, Moghazy A, et al. Effect of education on disease activity and functional status in rheumatoid arthritis patients. Egypt Rheumatol. 2021;43(1):7-11. doi:10.1016/j.ejr.2020.12.001

7. Zhang L, Xia Y, Zhang Q, et al. The correlations of socioeconomic status, disease activity, quality of life, and depression/anxiety in Chinese patients with rheumatoid arthritis. Psychol Health Med. 2017;22(1):28-36. doi:10.1080/13548506.2016.1198817

8. Callhoff J, Ramos AL, Zink A, Hoffmann F, Albrecht K. The association of low income with functional status and disease burden in German patients with rheumatoid arthritis: results of a cross-sectional questionnaire survey based on claims data. J Rheumatol. 2017;44 (6):766-772. doi:10.3899/jrheum.160966

9. Al-Bishri J, Attar S, Bassuni N, et al. Comorbidity profile among patients with rheumatoid arthritis and the impact on prescriptions trend. Clin Med Insights Arthritis Musculoskelet Disord. 2013;6 (CMAMD):S11481.

10. Hammam N, Gheita TA. Impact of secondhand smoking on disease activity in women with rheumatoid arthritis. Clin Rheumatol. 2017;36 (11):2415-2420. doi:10.1007/s10067-017-3795-2

11. Rydell E, Forslind K, Nilsson J-Å, Jacobsson LT, Turesson C. Smoking, body mass index, disease activity, and the risk of rapid radiographic progression in patients with early rheumatoid arthritis. Arthritis Res Ther. 2018;20(1):1-11. doi:10.1186/s13075-018-1575-2

12. Roelsgaard IK, Thomsen T, Østergaard M, et al. The effect of an intensive smoking cessation intervention on disease activity in patients with rheumatoid arthritis: study protocol for a randomised controlled trial. Trials. 2017;18(1):1-11. doi:10.1186/s13063-0172309-5

13. Nezamoleslami S, Ghiasvand R, Feizi A, Salesi M, Pourmasoumi M. The relationship between dietary patterns and rheumatoid arthritis: a case-control study. Nutr Metab. 2020;17(1):1-8. doi:10.1186/ s12986-020-00502-7

14. Philippou E, Nikiphorou E. Are we really what we eat? Nutrition and its role in the onset of rheumatoid arthritis. Autoimmun Rev. 2018;17 (11):1074-1077. doi:10.1016/j.autrev.2018.05.009
15. Rambod M, Nazarinia M, Raieskarimian F. The impact of dietary habits on the pathogenesis of rheumatoid arthritis: a case-control study. Clin Rheumatol. 2018;37(10):2643-2648. doi:10.1007/ s10067-018-4151-x

16. Paul B, Pariyapurath R. Risk factor assessment of rheumatoid arthritis in North Kerala. Eur J Rheumatol. 2018;5(3):184. doi:10.5152/ eurjrheum.2018.17111

17. Parks CG, Hoppin JA, De Roos AJ, Costenbader KH, Alavanja MC, Sandler DP. Rheumatoid arthritis in agricultural health study spouses: associations with pesticides and other farm exposures. Environ Health Perspect. 2016;124(11):1728-1734. doi:10.1289/EHP129

18. Murphy D, Hutchinson D. Is male rheumatoid arthritis an occupational disease? A review. Open Rheumatol J. 2017;11:88. doi: $10.2174 / 1874312901711010088$

19. Turk JN, Zahavi ER, Gorman AE, Murray K, Turk MA, Veale DJ. Exploring the effect of alcohol on disease activity and outcomes in rheumatoid arthritis through systematic review and meta-analysis. Sci Rep. 2021;11(1):1-6. doi:10.1038/s41598-021-89618-1

20. Kingsbury C, Karelis AD, Hains-Monfette G, Bernard P. Association between daily level of objective physical activity and C-Reactive protein in a representative national sample of adults with self-reported diagnosed arthritis or fibromyalgia. Rheumatol Int. 2020;40(9):1463-1471. doi:10.1007/s00296-020-04571-y

21. Bergström U, Jacobsson LT, Nilsson J-Å, Berglund G, Turesson C. Pulmonary dysfunction, smoking, socioeconomic status and the risk of developing rheumatoid arthritis. Rheumatology. 2011;50 (11):2005-2013. doi:10.1093/rheumatology/ker258

22. McInnes IB, Schett G. Pathogenetic insights from the treatment of rheumatoid arthritis. The Lancet. 2017;389(10086):2328-2337. doi:10.1016/S0140-6736(17)31472-1

23. Dai Y, Wang W, Yu Y, Hu S. Rheumatoid arthritis-associated interstitial lung disease: an overview of epidemiology, pathogenesis and management. Clin Rheumatol. 2020;40:1-10.

24. Yoshii I, Chijiwa T, Sawada N. Influence of pain score measured by a visual analog scale (PS-VAS) on the Health Assessment Questionnaire Disability Index and 28-joint Disease Activity Index with C-reactive protein in rheumatoid arthritis patients. Int $J$ Rheum Dis. 2018;21(11):1955-1961. doi:10.1111/1756-185X.13351

25. Favalli EG, Biggioggero M, Crotti C, Becciolini A, Raimondo MG, Meroni PL. Sex and management of rheumatoid arthritis. Clin Rev Allergy Immunol. 2019;56(3):333-345. doi:10.1007/s12016-018-8672-5

26. Dessie G, Tadesse Y, Demelash B, Genet S. Assessment of serum lipid profiles and high-sensitivity C-reactive protein among patients suffering from rheumatoid arthritis at Tikur Anbessa Specialized Hospital, Addis Ababa, Ethiopia: a cross-sectional study. Open Access Rheumatol. 2020;12:223. doi:10.2147/OARRR.S264466

27. He Y, Tang J, Wu B, Yang B, Ou Q, Lin J. Correlation between albumin to fibrinogen ratio, C-reactive protein to albumin ratio and Th17 cells in patients with rheumatoid arthritis. Clinica Chimica Acta. 2020;500:149-154. doi:10.1016/j.cca.2019.10.009

28. Takeuchi T, Miyasaka N, Inui T, et al. High titers of both rheumatoid factor and anti-CCP antibodies at baseline in patients with rheumatoid arthritis are associated with increased circulating baseline TNF level, low drug levels, and reduced clinical responses: a post hoc analysis of the RISING study. Arthritis Res Ther. 2017;19(1):1-11.

29. Berendsen ML, van Maaren MC, Arts EE, den Broeder AA, Popa CD, Fransen J. Anticyclic citrullinated peptide antibodies and rheumatoid factor as risk factors for 10-year cardiovascular morbidity in patients with rheumatoid arthritis: a large inception cohort study. J Rheumatol. 2017;44(9):1325-1330. doi:10.3899/jrheum.160670

30. Olsson ÅR, Skogh T, Axelson O, Wingren G. Occupations and exposures in the work environment as determinants for rheumatoid arthritis. Occup Environ Med. 2004;61(3):233-238. doi:10.1136/ oem.2003.007971 
31. Morotti A, Sollaku I, Franceschini F, et al. Systematic review and meta-analysis on the association of occupational exposure to free crystalline silica and rheumatoid arthritis. Clin Rev Allergy Immunol. 2021;Online ahead of print. doi:10.1007/s12016-02108846-5

32. Yang D-H, Huang J-Y, Chiou J-Y, Wei J-C-C. Analysis of socioeconomic status in the patients with rheumatoid arthritis. Int J Environ Res Public Health. 2018;15(6):1194. doi:10.3390/ ijerph15061194
33. Yang W-M, Zhang W-H, Ying H-Q, et al. Two new inflammatory markers associated with disease activity score-28 in patients with rheumatoid arthritis: albumin to fibrinogen ratio and C-reactive protein to albumin ratio. Int Immunopharmacol. 2018;62:293-298. doi:10.1016/j.intimp.2018.07.007

34. Andersson ML, Bergman S, Söderlin MK. The effect of socioeconomic class and immigrant status on disease activity in rheumatoid arthritis: data from BARFOT, a multi-centre study of early RA. Open Rheumatol J. 2013;7:105. doi:10.2174/1874312901307010105

\section{Publish your work in this journal}

Open Access Rheumatology Research and Reviews is an international, peer-reviewed, open access journal publishing original research, reports, editorials, reviews and commentaries on all aspects of clinical and experimental rheumatology in the clinic and laboratory including the following topics: Pathology, pathophysiology of rheumatological diseases; Investigation, treatment and management of rheumatological diseases; Clinical trials and novel pharmacological approaches for the treatment of rheumatological disorders. The manuscript management system is completely online and includes a very quick and fair peer-review system, which is all easy to use. Visit http://www.dovepress.com/testimonials.php to read real quotes from published authors. 